Supplementary information for

\title{
Palladium(II) immobilized on Metal-Organic Frameworks for catalytic Conversion of Carbon dioxide to formate
}

Piwai Tshuma, ${ }^{\mathrm{ab}}$ Banothile C.E Makhubela, ${ }^{\mathrm{b}}$ Nzondelelo Bingwa ${ }^{\mathrm{b}}$ Gift Mehlana*a

${ }^{a}$ Midlands State University, Faculty of Science and Technology, Department of Chemical Technology, Private Bag 9055 Senga Road, Gweru, Zimbabwe

${ }^{b}$ University of Johannesburg, Department of Chemistry, Faculty of Science, Kingsway Campus: C2 Lab 328, Auckland Park, 2006, South Africa

Email: mehlanag@staff.msu.ac.zw

Table S1. Crystal data and structure refinement for Pd@Mg:JMS-2a and Pd@Mn:JMS-2a

Empirical formula

Formula weight $\left(\mathrm{gmol}^{-1}\right) \quad 589.99$

Temperature/K

Crystal system

Space group

$\mathrm{a} / \AA$

$\mathrm{b} / \AA$

$\mathrm{c} / \AA$

$\alpha /^{\circ}$

$\beta /^{\circ}$

$\gamma / \circ$

Volume $/ \AA^{3}$

Z

Calculated

$\left(\mathrm{g} / \mathrm{cm}^{3}\right)$

$\mu(\mathrm{Mo}-\mathrm{K} \alpha) / \mathrm{mm}^{-1}$

$F(000)$
293(2)

monoclinic

C2/c

27.219(2)

7.7588(6)

$22.3190(17)$

90

102.764(2)

90

4596.8.9(6)

8

density

1.7048

1.11

2288
$\mathrm{C}_{18} \mathrm{H}_{20} \mathrm{~N}_{4} \mathrm{O}_{6} \mathrm{Mn}_{1} \mathrm{Pd}_{1} \mathrm{Cl}_{2}$

620.62

293(2)

monoclinic

$\mathrm{C} 2 / \mathrm{c}$

27.534(4)

7.8567(12)

$22.470(4)$

90

102.681(4)

90

4742.3(13)

8

1.55

2184 
Crystal size $/ \mathrm{mm}^{3}$

Radiation

$2 \theta \mathrm{Max} /{ }^{\circ}$

Index ranges

Reflections collected

No. unique data

Goodness of fit on S

Final $R$ indexes $[\mathrm{I}>=2 \sigma$

(I)]

$$
0.431 \times 0.379 \times 0.211
$$

$0.18 \times 0.15 \times 0.12$

$\operatorname{MoK} \alpha(\lambda=0.71073)$

52.12

56.63

$-33 \leq \mathrm{h} \leq 33,-9 \leq \mathrm{k} \leq 9,-27 \leq 1 \leq-36 \leq \mathrm{h} \leq 36,-10 \leq \mathrm{k} \leq 10,-27 \leq 1 \leq$ 27 27

60468

Final $\mathrm{wR}_{2}$ indexes [all 0.0882 data]

Deepest hole

$-0.38$
5897

1.035

0.0380

0.0911

$-0.42$

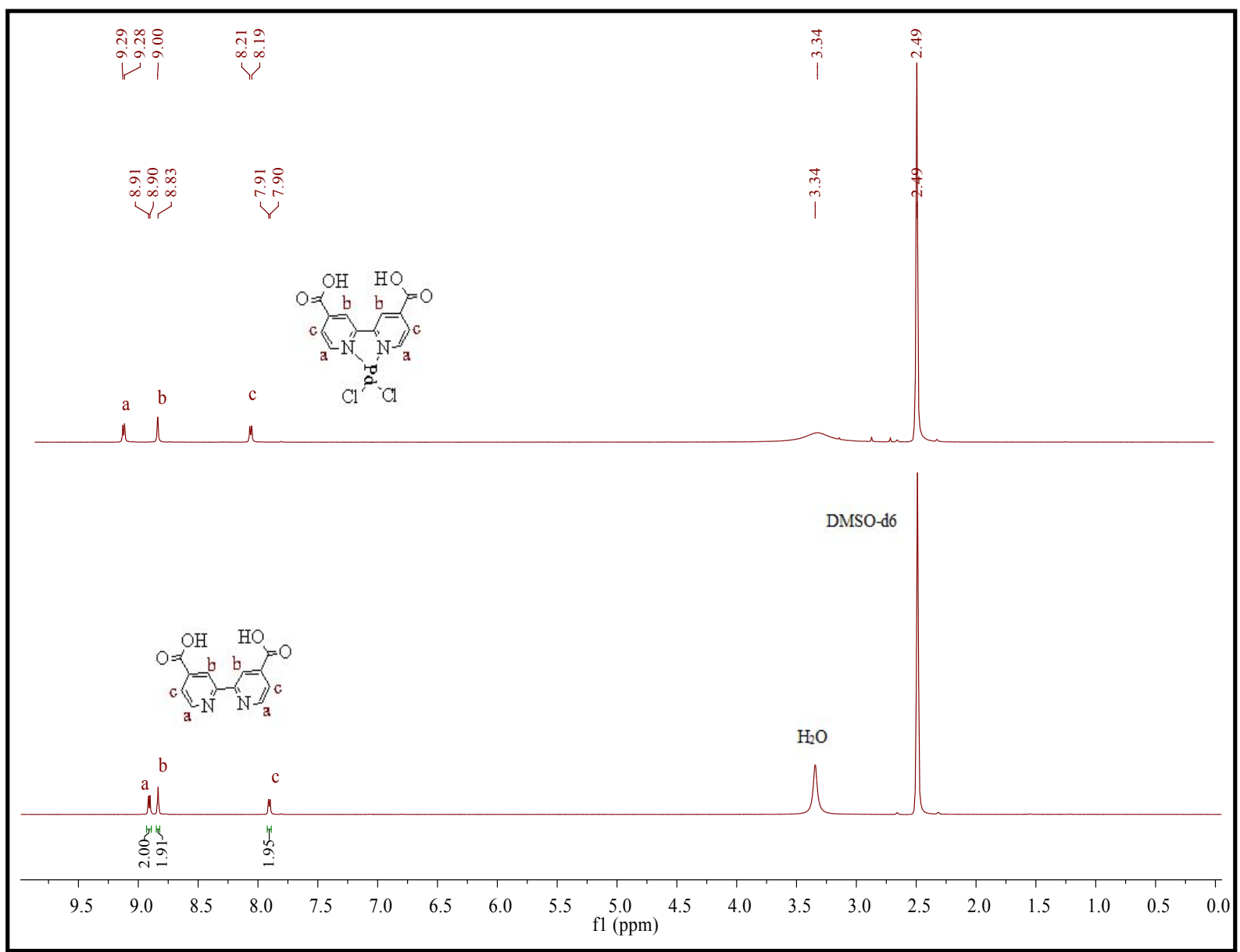

Figure S1: ${ }^{1} \mathrm{H}$ NMR spectrum of bpdc and C1 in DMSO-d da $_{6} 30^{\circ} \mathrm{C}$. 


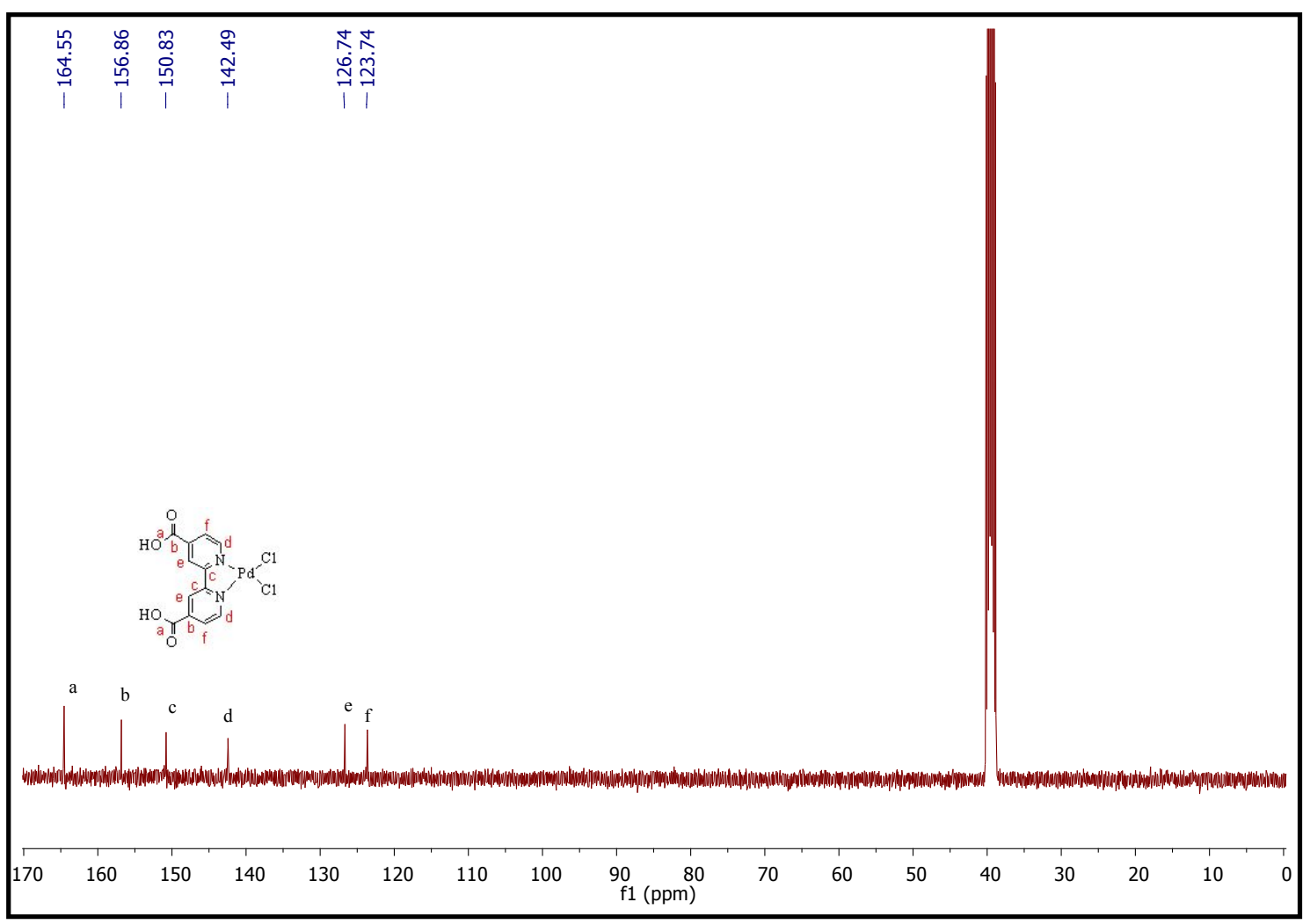

Figure $\mathrm{S} 2:{ }^{13} \mathrm{C}$ NMR spectrum of $\mathrm{C} 1$ in DMSO- $\mathrm{d}_{6}$.

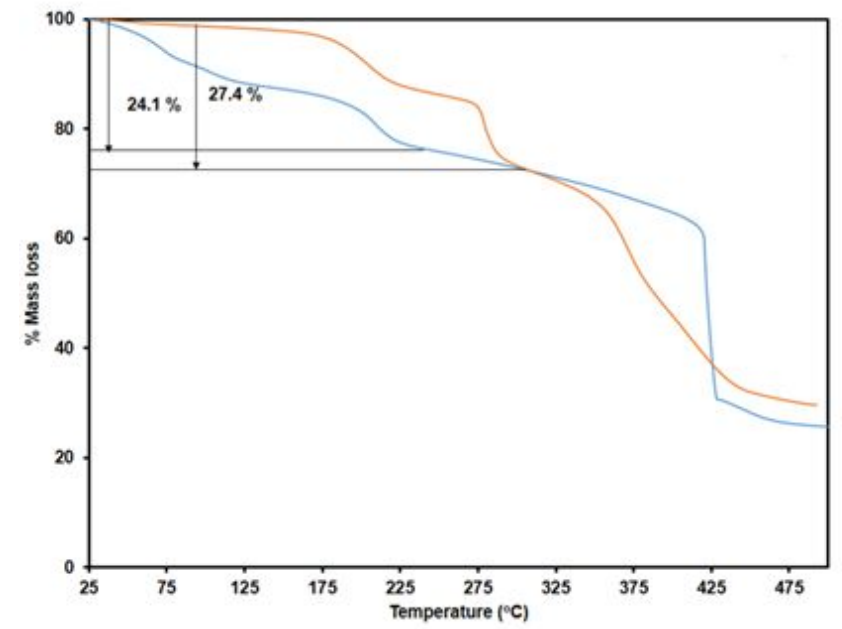

Figure S3: TGA traces of the as-synthesised compound Pd@Mg:JMS-2 (blue) and Pd@Mn:JMS-2 (orange). 


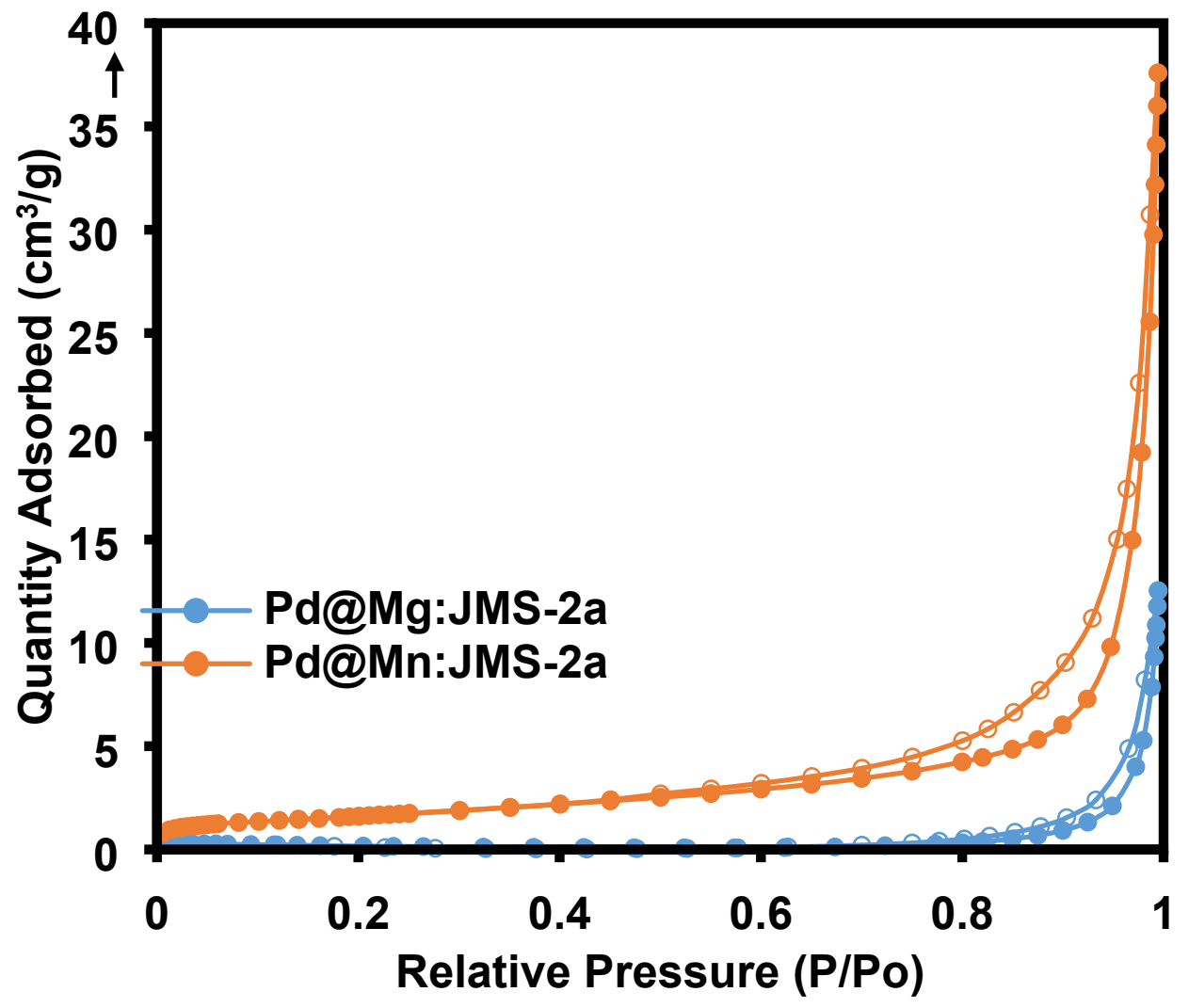

Figure S4: Nitrogen Sorption studies at 77K for Pd@Mn:JMS-2a (orange) and Pd@Mg:JMS2a (blue) 


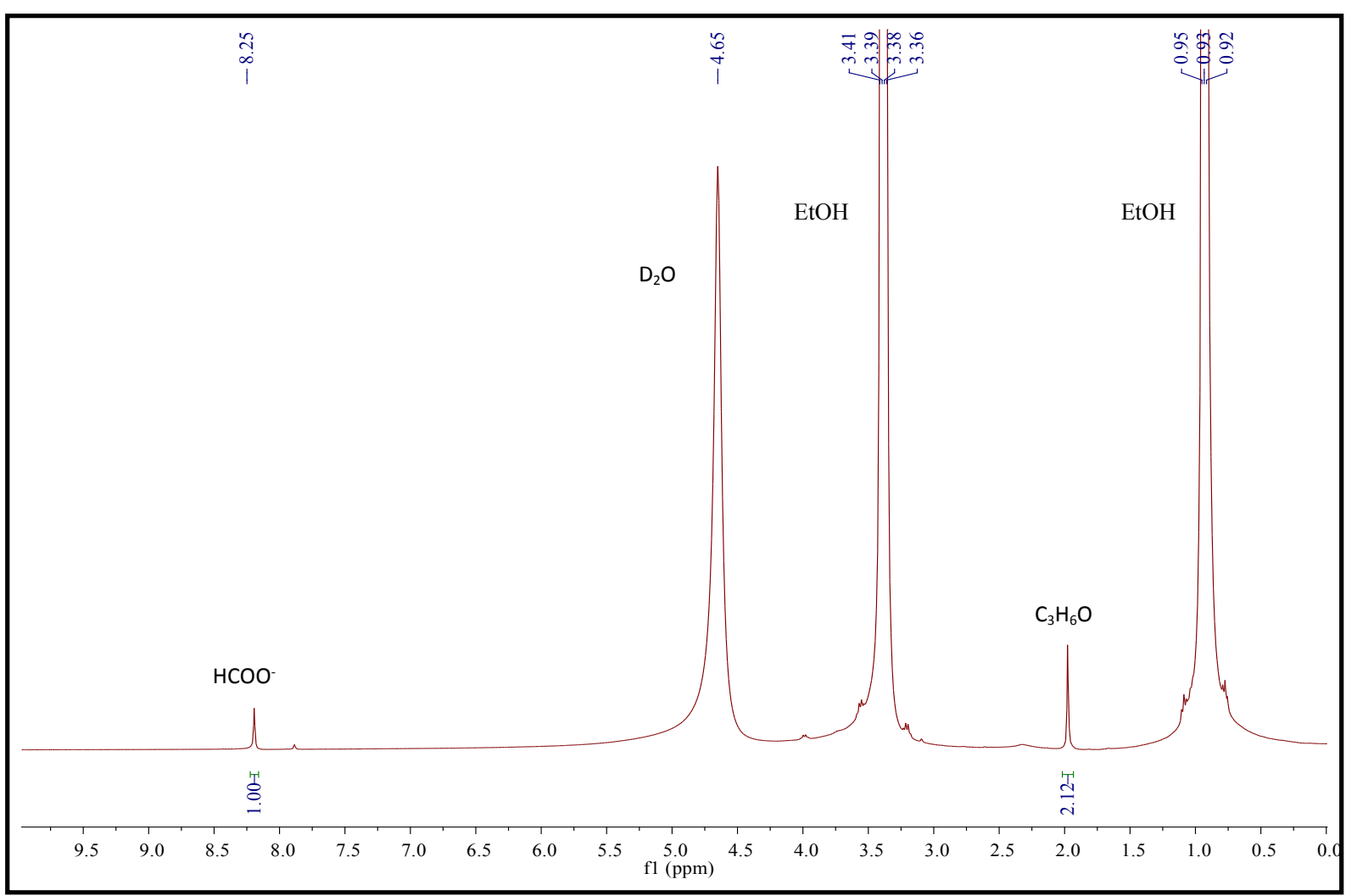

Figure S5. ${ }^{1} \mathrm{H}$ NMR for the reaction solution catalysed by Pd@Mn:JMS-2a under optimised conditions.

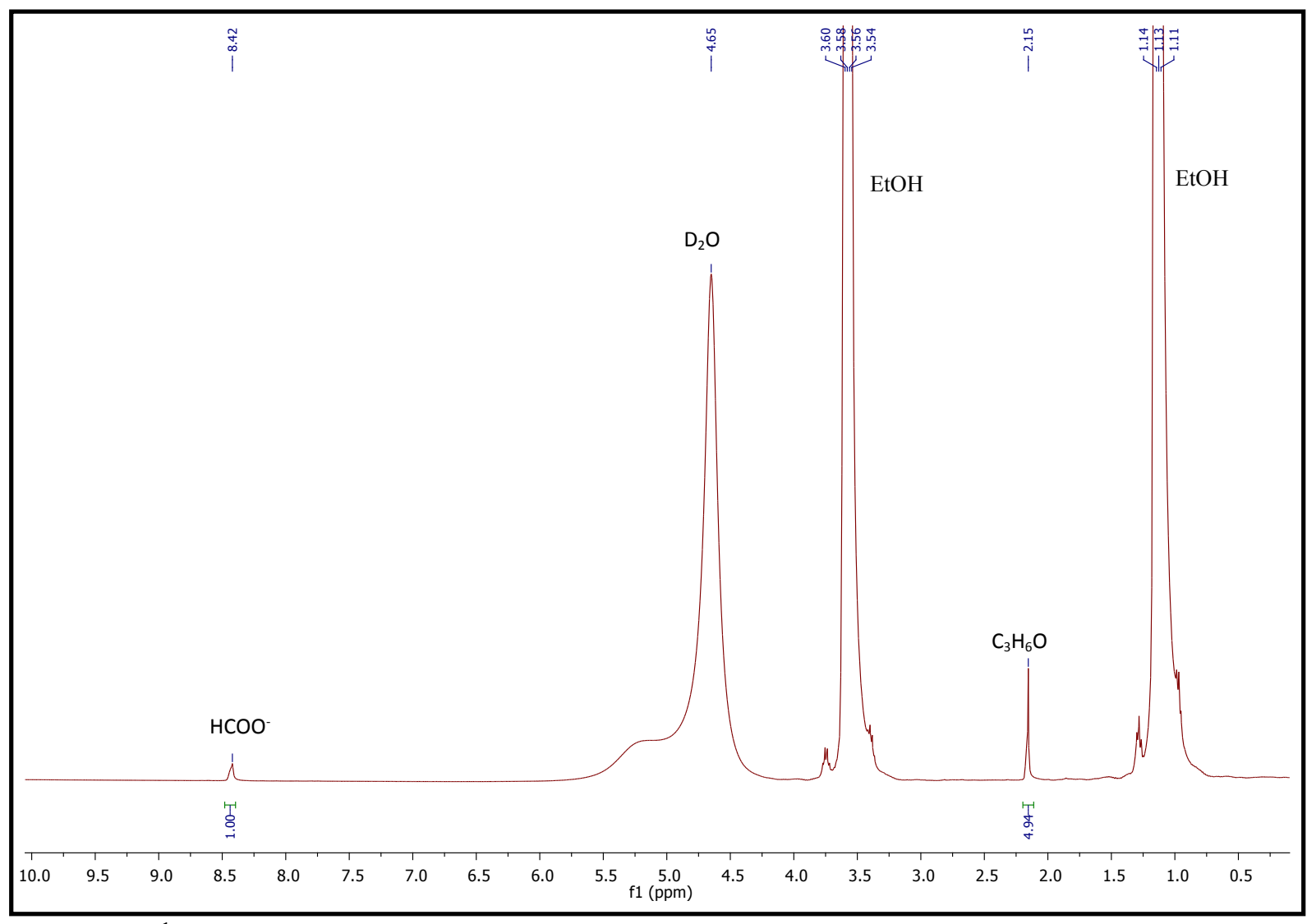

Figure S6. ${ }^{1} \mathrm{H}$ NMR for the reaction solution catalysed by $\mathrm{C} 1$ under optimised conditions. 


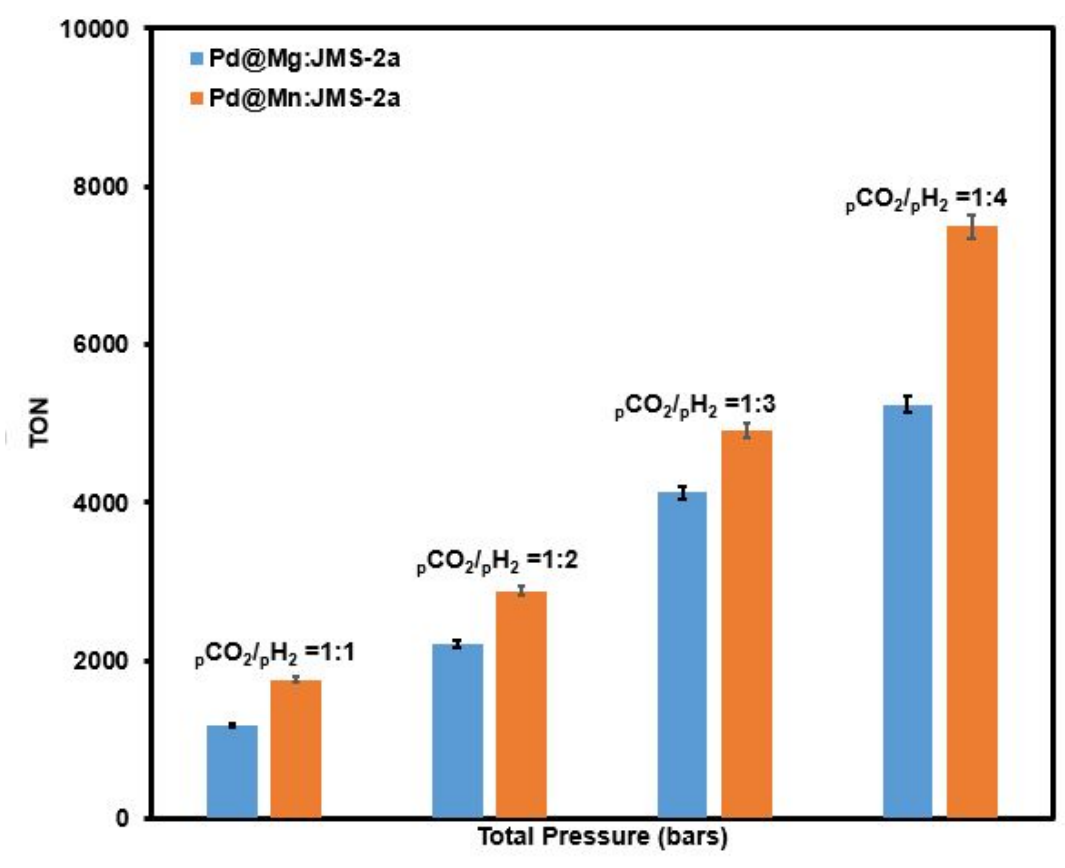

Figure S7. Effect of pressure (Conditions: Temp $90{ }^{\circ} \mathrm{C}, 15.6 \mu \mathrm{mol}$ catalyst loading, $5 \mathrm{mmol}$ KOH and 8 mL ethanol, time 24 hours): blue Pd@Mg:JMS-2a and orange Pd@Mn:JMS-2a.

Table S2. Comparative study of the heterogeneous catalytic systems for the hydrogenation of $\mathrm{CO}_{2}$ to formate.

\begin{tabular}{|c|c|c|c|c|c|c|}
\hline Catalyst & $\mathrm{pH}_{2} / \mathrm{pCO}_{2}$ (bars) & Temp $/{ }^{\circ} \mathrm{C}$ & Time $/ \mathrm{hr}$ & TON & TOF & Ref \\
\hline MbpyOH-[Ir $\left.{ }^{\mathrm{III}}\right]-\mathrm{UiO}$ & 1 & 85 & 15 & 6149 & 410 & 1 \\
\hline Ru@UiO-66 & 15 & 27 & 0.5 & 32000 & 64000 & 2 \\
\hline $\operatorname{IrCp} *(\mathrm{HBF}-2) \mathrm{Cl}_{2}$ & 80 & 120 & 10 & 6400 & 640 & 3 \\
\hline Bpy-CTF-Ru(acac $)_{2} \mathrm{Cl}$ & 80 & 120 & 5 & 21200 & 4240 & 4 \\
\hline $\operatorname{IrCp} *(\mathrm{~N}-\mathrm{N}) \mathrm{x}\} \mathrm{y} / \mathrm{HBF}$ & 40 & 120 & 10 & 6400 & 640 & 3 \\
\hline Ru-HT & 60 & 60 & 24 & 11389 & 475 & 5 \\
\hline Nitrogen rich g-C NPs & 62 & 120 & 24 & 82265 & 3427 & 6 \\
\hline $\mathrm{Pd} @ M g: J M S-2 \mathrm{a}$ & 50 & 100 & 24 & 9808 & 408 & This work \\
\hline Pd@Mn:JMS-2a & 50 & 100 & 24 & 7272 & 303 & This work \\
\hline
\end{tabular}

TON $=$ Turnover number: moles of product formed per moles of active metal centre

\section{Poisoning studies}

Table S3. Retained activity in the presence of differently sized thiols 


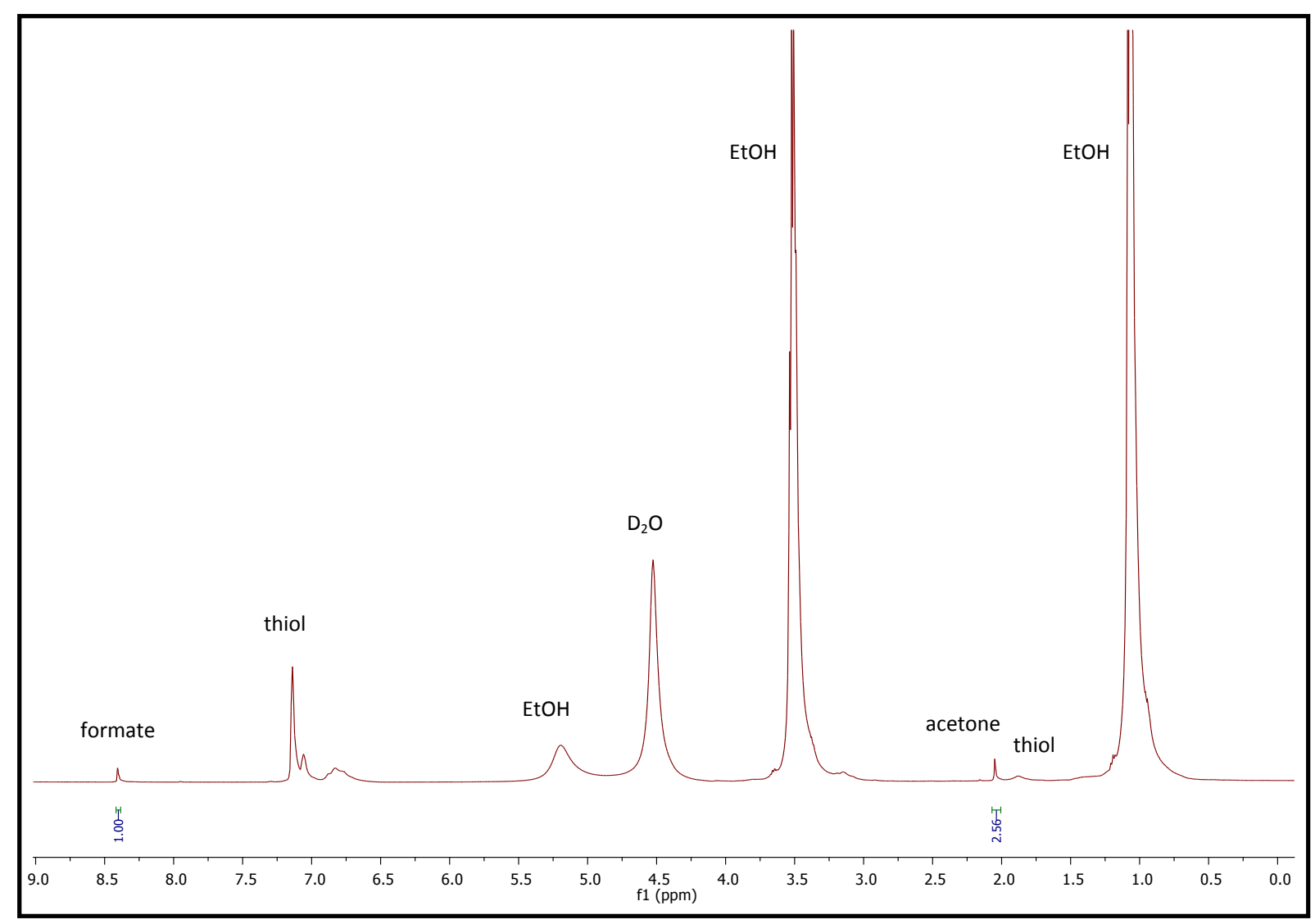

Figure S8. Catalysis in the presence of benzylmercaptan 


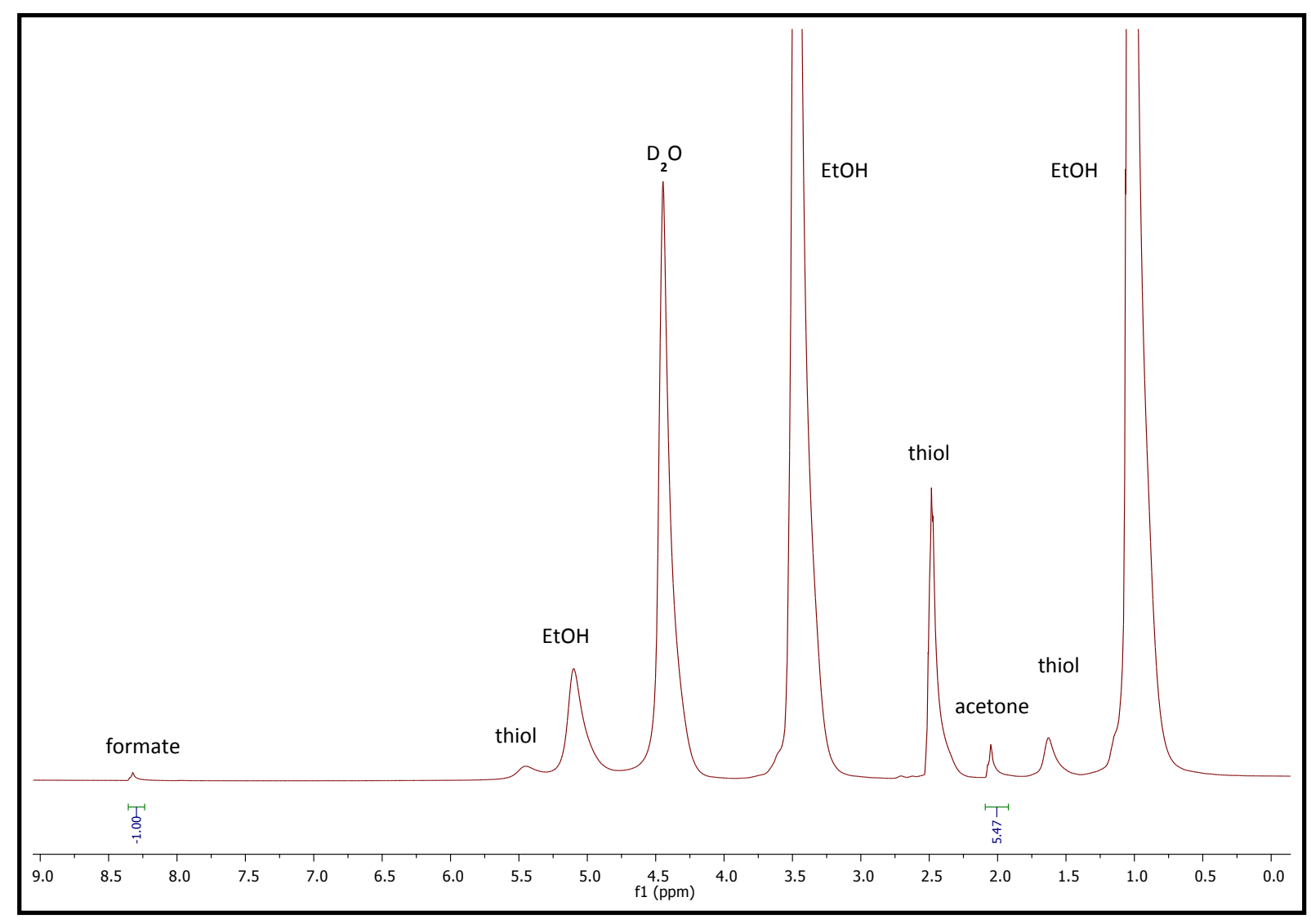

Figure S9. Catalysis in the presence of 2 mercapto-ethano
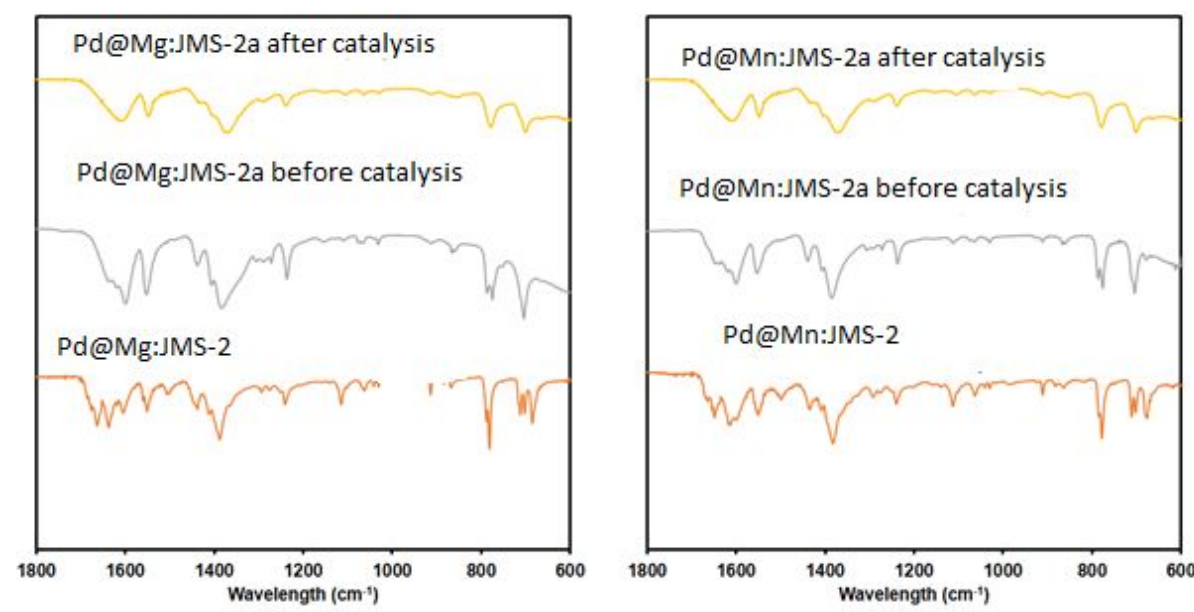

Figure S10. FTIR of Pd@Mg:JMS-2a and Pd@Mn:JMS-2a before and after catalysis 

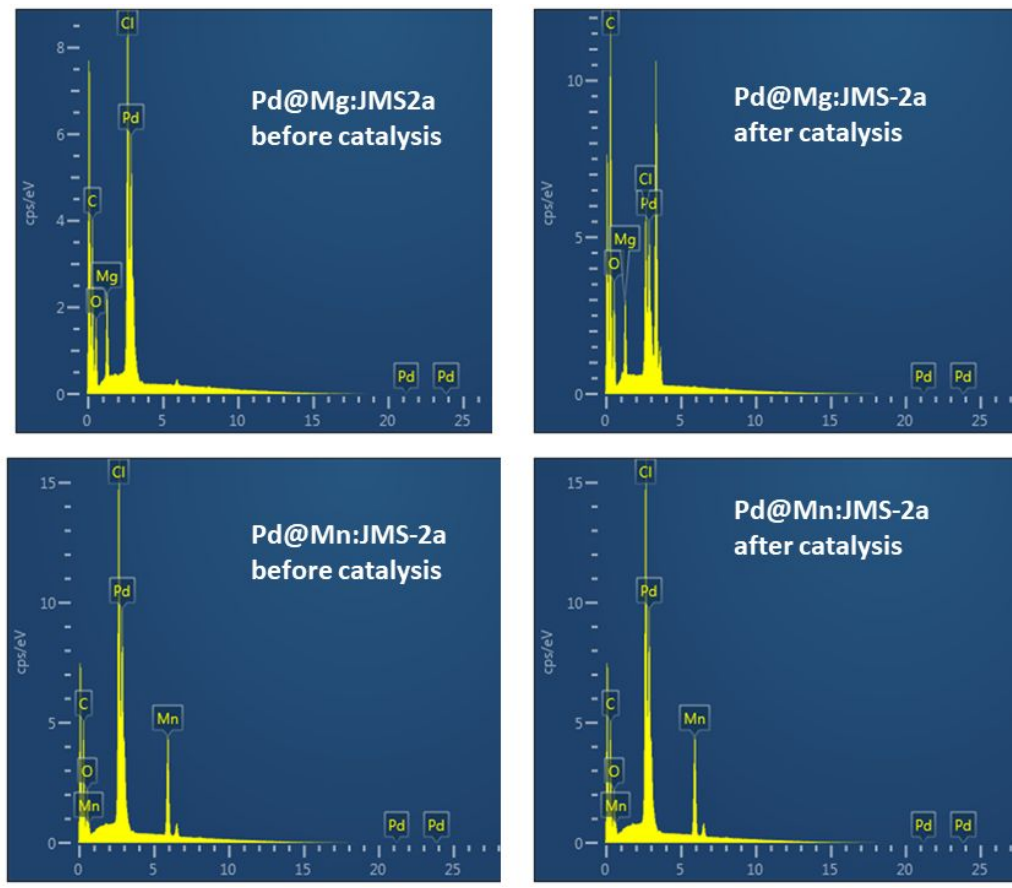

Figure S11: EDX analysis of the fresh and recovered catalysts
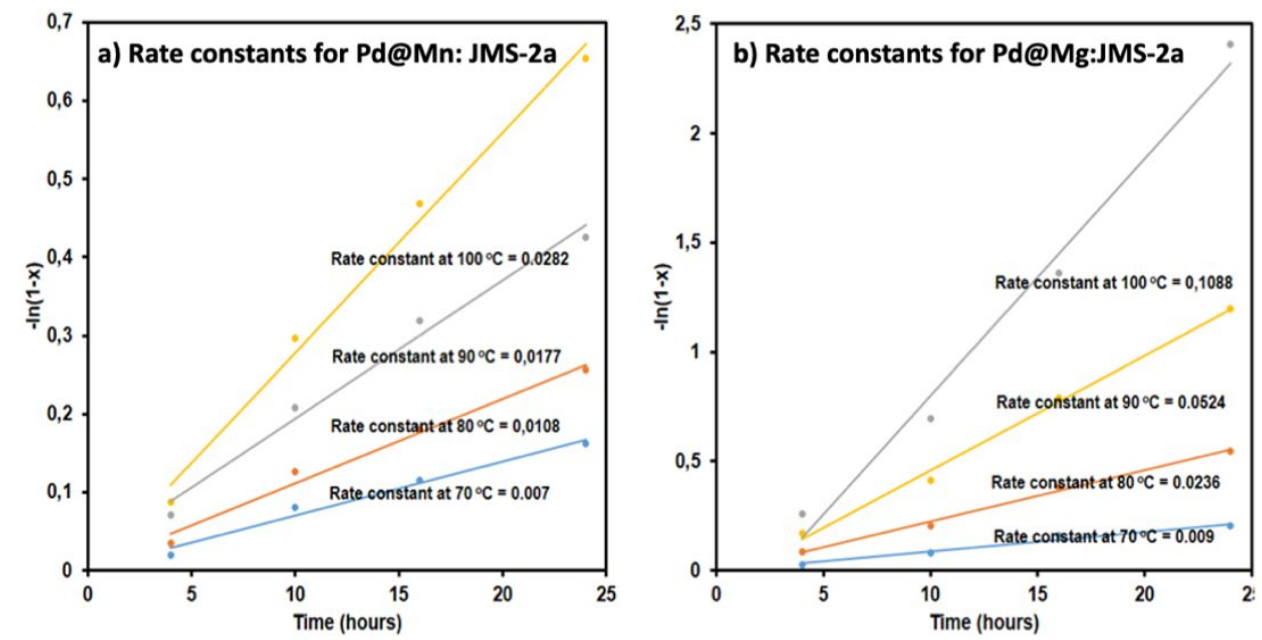

Figure S12: Rate Constants for the formation of formate by (a) Pd@Mn:JMS-2a and (b) Pd@Mg:JMS-2a

Table S4: Rate constant $(\mathrm{k})$ at different temperatures 
70

80

90

100
0.0070

0.0108

0.0177

0.0282
0.0090

0.0236

0.0524

0.1088

\section{References}

(1) An, B.; Zeng, L.; Jia, M.; Li, Z.; Lin, Z.; Song, Y.; Zhou, Y.; Cheng, J.; Wang, C.; Lin,

W. Molecular Iridium Complexes in Metal-Organic Frameworks Catalyze $\mathrm{CO}_{2}$ Hydrogenation via Concerted Proton and Hydride Transfer. J. Am. Chem. Soc. 2017, 139 (49), 17747-17750.

(2) Li, Z.; Rayder, T. M.; Luo, L.; Byers, J. A.; Tsung, C. Aperture-Opening Encapsulation of a Transition Metal Catalyst in a Metal-Organic Framework for $\mathrm{CO}_{2}$ Hydrogenation. J. Am. Chem. Soc. 2018, 140 (26), 8082-8085.

(3) Gunniya Hariyanandam, G.; Hyun, D.; Natarajan, P.; Jung, K. D.; Yoon, S. An Effective Heterogeneous Ir(III) Catalyst, Immobilized on a Heptazine-Based Organic Framework, for the Hydrogenation of $\mathrm{CO}_{2}$ to Formate. Catal. Today 2016, 265, 52-

(4) Gunasekar, G. H.; Shin, J.; Jung, K.-D.; Park, K.; Yoon, S. Design Strategy toward Recyclable and Highly Efficient Heterogeneous Catalysts for the Hydrogenation of $\mathrm{CO}_{2}$ to Formate. ACS Catal. 2018, 8, 4346-4353.

(5) Maru, M. S.; Ram, S.; Shukla, R. S.; Khan, N. H. Ruthenium-Hydrotalcite (Ru-HT) as 
an Effective Heterogeneous Catalyst for the Selective Hydrogenation of $\mathrm{CO}_{2}$ to Formic Acid. Mol. Catal. 2018, 446, 23-30.

(6) Patel, P.; Nandi, S.; Maru, M. S.; Kureshy, R. I.; Khan, N.-U. H. Nitrogen-Rich Graphitic Carbon Stabilized Cobalt Nanoparticles as an Effective Heterogeneous Catalyst for Hydrogenation of $\mathrm{CO}_{2}$ to Formate. J. $\mathrm{CO}_{2}$ Util. 2018, 25 , 310-314. 